\title{
Intravoxel incoherent motion magnetic resonance imaging: basic principles and clinical applications
}

\author{
Aleksandra E. Szubert-Franczak ${ }^{1 \mathrm{~A}, \mathrm{E}, \mathrm{F}}$, Martyna Naduk-0strowska ${ }^{1 \mathrm{~A}, \mathrm{E}, \mathrm{F}}$, Katarzyna Pasicz ${ }^{2 \mathrm{2A,E}, \mathrm{F}}$, \\ Joanna Podgórska ${ }^{1,3 E, F}$, Witold Skrzyński' ${ }^{2}$, Andrzej Cieszanowski ${ }^{1,, E, F}$ \\ 'Department of Radiology I, Maria Sklodowska-Curie National Research Institute of Oncology, Warsaw, Poland \\ ${ }^{2}$ Department of Medical Physics, Maria Sklodowska-Curie National Research Institute of Oncology, Warsaw, Poland \\ ${ }^{3} 2^{\text {nd }}$ Department of Clinical Radiology, Medical University of Warsaw, Warsaw, Poland
}

\section{Abstract}

\begin{abstract}
The purpose of this article was to show basic principles, acquisition, advantages, disadvantages, and clinical applications of intravoxel incoherent motion (IVIM) magnetic resonance imaging (MRI). IVIM MRI as a method was introduced in the late 1980s, but recently it started attracting more interest thanks to its applications in many fields, particularly in oncology and neuroradiology. This imaging technique has been developed with the objective of obtaining not only a functional analysis of different organs but also different types of lesions. Among many accessible tools in diagnostic imaging, IVIM MRI aroused the interest of many researchers in terms of studying its applicability in the evaluation of abdominal organs and diseases. The major conclusion of this article is that IVIM MRI seems to be a very auspicious method to investigate the human body, and that nowadays the most promising clinical application for IVIM perfusion MRI is oncology. However, due to lack of standardisation of image acquisition and analysis, further studies are needed to validate this method in clinical practice.
\end{abstract}

Key words: magnetic resonance imaging, diffusion-weighted imaging, intravoxel incoherent motion.

\section{Introduction}

The intravoxel incoherent motion (IVIM) diffusionweighted (DW) model as a possible imaging technique, using multiple $b$ values and bi-exponential fitting for the concurrent estimation of the pure molecular water diffusion and microcirculation of blood water in randomly oriented capillaries (perfusion) was first introduced in the late 1980 s by Le Bihan et al. [1]. The idea to use diffusion and IVIM magnetic resonance imaging (MRI) to acquire perfusion parameter maps was considered revolutionary but technically difficult, and, as a result, it was more than 20 years before the method started being used in clinical practice [2]. IVIM reflects the random microscopic motion of water molecules that occurs in each voxel on MR images not only in intra- or extracellular space but also in microcirculation of blood [3]. According to IVIM theory, diffusion and perfusion are affected by several tissue characteristics, including the presence of restrictive barriers within tissue, the viscosity of the fluid in which the spins are diffusing, and the velocity and fractional volume of perfusing spins [4]. Formerly, due to degradation of images caused by cardiac, respiratory, and other motion artifacts, IVIM imaging was restricted to neuroradiologic applications. Nowadays, it is pursued to apply IVIM MRI to evaluate almost entire human body. Over the last few

\section{Correspondence address:}

Martyna Naduk-0strowska, Department of Radiology I, Maria Sklodowska-Curie National Research Institute of Oncology, 5 Roentgena St., 02-781 Warsaw,

Poland, e-mail: naduk.martyna@gmail.com

Authors' contribution:

A Study design · B Data collection - C Statistical analysis · D Data interpretation - E Manuscript preparation · F Literature search · G Funds collection 
years there has been a revival of interest in IVIM MRI and its applications in many fields, particularly in oncology [2].

\section{Basic principles and acquisition of intravoxel incoherent motion perfusion magnetic resonance imaging}

DW magnetic resonance imaging is based on the random movement of individual water protons, called Brownian motion. The Brownian motion can be described by a series of molecular jumps [5].

According to Einstein's equation the diffusion coefficient $D$ depends on the averages of individual displacements between two collisions and the mean molecular velocity. In the presence of a magnetic field, random displacement of individual molecules between two gradient pulses results in signal attenuation. Initially, the signal attenuation increase was described by a monoexponential function:

$$
\frac{S}{S_{0}}=\exp (-b \times D)
$$

where: $S$ is the measured signal intensity, $S_{0}$ is the signal intensity without the influence of diffusion, $D\left(\mathrm{~mm}^{2} / \mathrm{s}\right)$ is the diffusion coefficient of water, and the $b$ value $\left(\mathrm{s} / \mathrm{mm}^{2}\right)$ can be calculated as follows: $\gamma$ - gyromagnetic ratio $(\mathrm{MHz} / \mathrm{T})$, $G$ - amplitude of the two diffusion gradient pulses $(\mathrm{mT} / \mathrm{m})$, $\delta$ - duration of the pulses (ms), $\Delta-$ time between the two pulses (ms) [1].

The assumptions of the IVIM model, described for the first time by Le Bihan et al. in the late 1980s, are based on the translation movements at voxel levels. Microcirculation of the blood in the capillary network would mimic a pseudodiffusion process [1]. The IVIM effect appears at low $b$ values (i.e. $b \leq 200 \mathrm{~s} / \mathrm{mm}^{2}$ ) as a deviation of tissue diffusion signal decay (Figure 1). Because the pseudo-diffusion coefficient $\left(D^{*}\right)$ is one order of magnitude higher than the diffusion coefficient $D$, the exponential decay with the pseudo-diffusion coefficient disappears faster. At low $b$-values, the perfusion effect predominantly contributes to the overall diffusion signal. At higher values of $b$, the exponential input with $D$ modifies the signal. MRI signal attenuation is the sum of

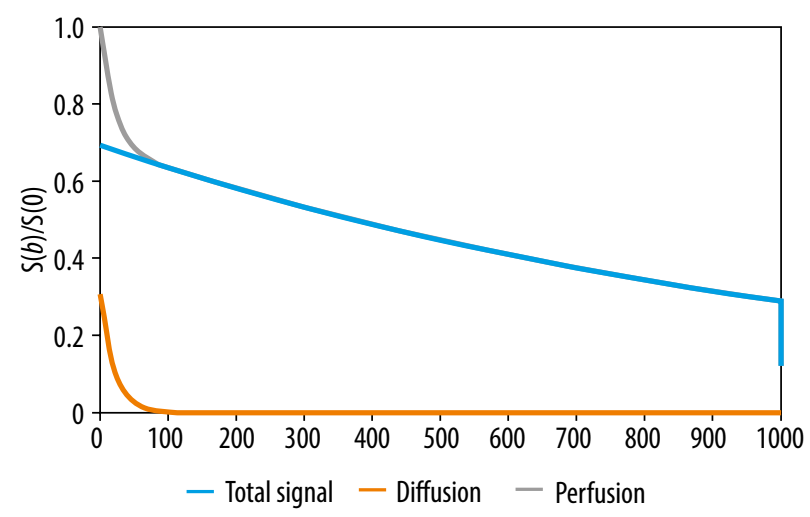

Figure 1. The intravoxel incoherent motion effect the tissue and blood component, taking the shape of biexponential decay:

$$
\frac{S}{S_{0}}=(I-f) \times \exp (-b \times D)+f \times \exp \left(-b \times\left(D^{*}+D\right)\right)
$$

where: $S$ - the signal intensity in the pixel with diffusion gradient $b, S_{0}$ - the signal intensity in the pixel without diffusion gradient, $D$ - the true diffusion as reflected by pure molecular diffusion $\left(\mathrm{mm}^{2} / \mathrm{s}\right), f-$ the fractional perfusion related to microcirculation, and $D^{*}$ - pseudo-diffusion coefficient representing perfusion related diffusion or incoherent microcirculation $\left(\mathrm{mm}^{2} / \mathrm{s}\right) . D^{*}$ is sometimes referred to as $\mathrm{ADC}_{\text {fast }}$, while $D$ may be also called $\mathrm{ADC}_{\text {slow }}$.

The IVIM sequence consists of several scans: the first without the use of a coding gradient, the next with different values of the amplitude and duration of the gradient (different $b$-values). An important part of the IVIM acquisition protocol is the choice of $b$-values (in terms of their number and distribution), resulting in a different degree of diffusion weighting in the acquired images. The $b$-values used in IVIM imaging are usually in the range of $0-900 \mathrm{~s} / \mathrm{mm}^{2}$. The number of $b$-values ranges from 4 to 16 . Number of $b$-values in the range of $0-200 \mathrm{~s} / \mathrm{mm}^{2}$, where the perfusion effect is dominant, is between 2 and 12 (Table 1).

There are, however, several important limitations that have so far prevented the use of IVIM in routine practice. The most important is the lack of a uniform data analysis method, which is particularly important because IVIM imaging is based on the quantitative analysis of $f, D$, and $D^{*}$ parameters $[1,5,6]$.

Le Bihan proposed acquisition with only three values of $b$ that are theoretically sufficient to obtain IVIM results. However, more points are needed, especially for the brain due to "noise contamination" [5]. For accurately estimating IVIM parameters at least 10 of the optimal distributed $b$-values should be used [7].

In addition, IVIM parameters, similarly to ADC values, are possibly field-strength dependent (1.5T vs. $3.0 \mathrm{~T})$ [8].

\section{Strengths and limitations of intravoxel incoherent motion magnetic resonance imaging}

Understanding of the strengths and limitations of IVIM concept may help to appreciate a clinical benefit of this method (Table 2).

The most important advantage of IVIM diffusion MR imaging is that as a non-contrast perfusion imaging modality it can be used in situations in which intravenous administration of contrast agents is not clinically justified, and it may serve as an interesting alternative to contrast-enhanced perfusion MR imaging in some patients with contraindications to contrast agents, such as severely compromised renal function. Furthermore, IVIM diffusion MR imaging does not involve ionising radiation or injection of radioisotopes.

The most important disadvantages include artifacts related to cardiac and respiratory motion, artifacts from 
Table 1. The $b$-value used in clinical trials

\begin{tabular}{|c|c|c|c|}
\hline Paper & Year & $b$-values $\left(\mathrm{s} / \mathrm{mm}^{2}\right)$ & Number of $b$-values \\
\hline Guo [9] & 2016 & $0,10,20,30,50,70,100,150,200,400,800,1000$ & 12 \\
\hline Liu [10] & 2013 & $0,10,20,30,50,70,100,150,200,400,800,1000$ & 12 \\
\hline Ichikawa [11] & 2013 & $0,10,20,30,40,50,80,100,200,400,800,1000$ & 8 \\
\hline Rheinheimer [12] & 2012 & {$[0 ; 50],[0 ; 100],[0 ; 150],[0 ; 200],[0 ; 300],[0 ; 400],[0 ; 600] ;[0 ; 800]$} & 8 \\
\hline Cui [13] & 2015 & $16 b$-values from 0 to 800 & 16 \\
\hline Dyvorne [14] & 2013 & $0,15,30,45,60,75,90,105,120,135,150,175,200,400,600,800$ & 16 \\
\hline Federau [15] & 2014 & $0,20,40,80,110,140,170,200,300,400,500,600,700,800,900$ & 15 \\
\hline Federau [16] & 2014 & $0,10,20,40,80,110,140,170,200,300,400,500,600,700,800,900$ & 16 \\
\hline Döpfert [17] & 2011 & $0,50,500,800$ & \\
\hline Kakite [18] & 2016 & $0,15,30,45,60,75,90,105,120,135,150,175,200,400,600,800$ & 16 \\
\hline Shim [19] & 2015 & $0,10,20,40,60,80,100,120,140,160,180,200,300,500,700,900$ & 16 \\
\hline Conklin [20] & 2016 & $0,10,20,40,80,110,140,170,200,300,400,500,600,700,800,900$ & 16 \\
\hline Federau [21] & 2016 & $0,10,20,40,80,110,140,170,200,300,400,500,600,700,800,900$ & 16 \\
\hline $\mathrm{Xu}[22]$ & 2016 & $0,10,20,30,40,50,60,70,80,90,100,200,400,800$ & 14 \\
\hline Boss [23] & 2016 & $0,10,30,60,120,200,300,430,600,800$ & 10 \\
\hline Valerio [24] & 2016 & $0,10,20,30,40,50,80,100,200,400,800$ & 11 \\
\hline Pang [25] & 2013 & $0,188,375,563,750$ & 5 \\
\hline Bane [26] & 2016 & $0,15,30,45,60,75,90,105,120,135,150,175,200,400,600,800$ & 16 \\
\hline
\end{tabular}

other bulk flow phenomena, no standardisation of acquisition parameters, and various algorithms used for quantitative image analysis. Moreover, the sensitivity of IVIM MRI not only varies according to vessel size but also depends on the utilised number and distribution of applied $b$ values. Thus, IVIM-derived parameters and maps are highly variable and inconsistent. Due to the lack of standardisation of the IVIM technique, significant variance in calculated parameters among studies has been observed and no values for normal organs have been established.

\section{Clinical applications in oncology}

\section{Abdominal and pelvic organs}

\section{Liver}

IVIM was applied to study liver diseases such as liver fibrosis, nonalcoholic liver fatty disease, and focal liver lesions and to estimate possible treatment response $[3,30]$. With IVIM DWI, Luciani et al. suggested that the diffusion component related to the molecular displacement $(D)$ does not differ significantly between cirrhotic and healthy livers [27].

Yamada et al. found that $D$ was significantly lower than ADC, thus suggesting that differences reported in ADC between patients with cirrhosis and healthy patients were mainly related to the perfusion component of liver diffusion. The fact that the pure molecular diffusion coefficient, $D$, was similar in both the healthy liver group and
Table 2. Advantages and disadvantages of intravoxel incoherent motion (IVIM) magnetic resonance imaging

\begin{tabular}{|l|l|}
\hline Advantages & Disadvantages \\
\hline Non-invasive technique & Cardiac and respiratory motion artifacts \\
\hline No use of contrast agents & Bulk flow phenomenon artifacts \\
\hline $\begin{array}{l}\text { No need of radioisotopes } \\
\text { injection }\end{array}$ & $\begin{array}{l}\text { No standardization of acquisition protocols } \\
\text { and models }\end{array}$ \\
\hline No ionizing radiation & $\begin{array}{l}\text { Variance in calculated parameters among } \\
\text { studies }\end{array}$ \\
\hline & Differential sensitivity to vessel size \\
\cline { 2 - 3 } & $\begin{array}{l}\text { Lack of standardization of calculation } \\
\text { of IVIM parametres }\end{array}$ \\
\cline { 2 - 2 } & No established values for normal organs \\
\hline
\end{tabular}

the cirrhotic liver group further indicates that changes in liver architecture may be of less importance than changes in liver perfusion [28] (Figure 2).

However, the large overlap of $D, f$, and $D^{*}$ for different stages of fibrosis suggests that this technique cannot be used to accurately characterise stages of liver fibrosis [27].

In a large number of studies the IVIM technique was used for the assessment of focal liver lesions. Liver nodules including hepatocellular carcinoma (HCC), haemangioma, focal nodular hyperplasias (FNH), and liver metastasis (MET) showed overlap in terms of IVIM parameters. However, other researchers, like Yamada et al., showed the potential of IVIM MRI to differentiate HCC from haemangiomas and cysts [28]. 

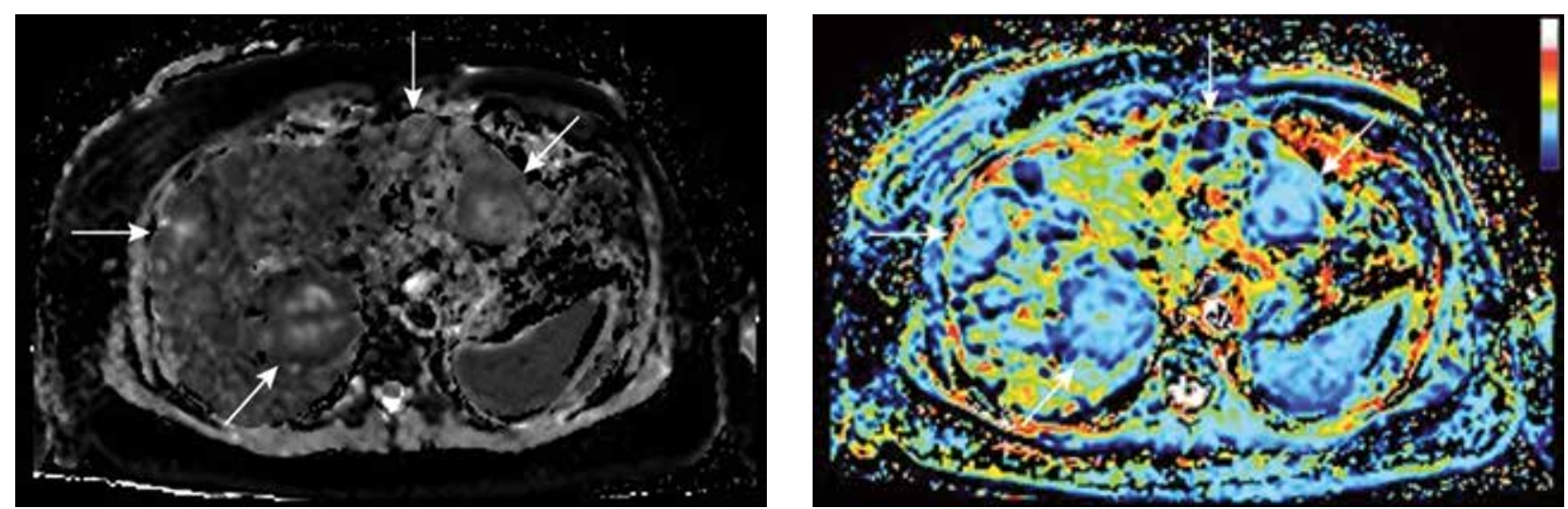

Figure 2. Sample quantitative maps of intravoxel incoherent motion (IVIM) parameters ( $D$ and $f$, respectively) created using own plugin for ImageJ software for breast cancer liver metastases (arrows). The increase in blood flow/volume occurring in liver metastases can be detected and mapped with IVIM magnetic resonance imaging

Summarising, IVIM MRI for assessing hepatic lesions imposes some difficulties, mainly due to the possible overlap between normal and diseased liver tissue, as well as between benign and malignant lesions [10].

\section{Pancreas}

IVIM imaging has recently gained interest as a method to properly recognise and characterise pancreatic lesions.

Perfusion-related IVIM-derived parameters seem especially auspicious for differentiation between normal pancreatic parenchyma and solid pancreatic lesions with high sensitivity and specificity [29].

According to Re et al. there is a compelling difference in the average IVIM perfusion fraction of pancreatic adenocarcinoma compared to healthy pancreatic tissue [31]. IVIM MRI emerges as a promising method for characterisation of pancreatic lesions and should therefore be further investigated.

\section{Kidney}

Over the past two decades, the number of properly diagnosed renal tumours has escalated due to increased utilisation of different imaging techniques. Unfortunately, preoperative classification of solid renal masses remains challenging and defective. In light of the above, in the past few years there have been attempts to use IVIM parameters to distinguish renal tumour subtypes. Chandarana et al. [32] established the differentiation of subtypes of renal cell carcinomas using perfusion fraction $(f)$ and tissue diffusivity $\left(D^{*}\right)$. Interestingly, the authors demonstrated a significantly higher $f$ and lower $D^{*}$ in enhancing renal masses compared with markedly and poorly enhancing renal masses, differentiating these two groups with a higher accuracy than standard ADC values [33]. The combination of $f$ and $D^{*}$ allowed the diagnosis of papillary renal cell carcinoma (RCC) and cystic RCC with 100\% accuracy, and clear cell RCC and chromophobe RCC with $86.5 \%$ accuracy. The $f$ was shown to have a good correlation under the curve of gadolinium concentration at 60 seconds, which is a measure of the gadolinium concentration obtained from the area under the gadolinium-enhancement signal intensity (SI) curve over the first 60 seconds (CIAUC60) after intravenous injection of contrast, which potentially enable the assessment of tumour vascularity without the need for intravenous administration of gadolinium contrast agent [32,34].

According to Ding et al. [35] IVIM-derived parameters, especially the perfusion-related parameters $\left(D^{\star}\right.$ and $\left.f\right)$, showed greater diagnostic accuracy than that of ADC values in differentiating non-ccRCCs from lipid-poor AMLs.

\section{Prostate}

Recent studies have reflected an interest in multiparametric MR imaging including diffusion MRI in the detection, staging, and post-treatment follow-up of prostate cancer [36].

The results of published papers utilising the IVIM model are inconsistent in terms of prostate cancer detection, staging, and treatment response. According to some studies, the diagnostic value of this technique compared to ADC is rather indigent [17] whereas others report showed significant differences between the IVIM parameters of benign and malignant tissue [24].

Concluding, there is a visible fluctuation between IVIM parameters in cancer and normal prostatic within the literature [37], and there is still a need for validation in the application of IVIM in the diagnosis of prostate cancer.

\section{Head and neck}

Over the last two decades IVIM imaging became a very promising technique for differentiation of tumours of the head and neck area, due to distinctive $f$ and $D$.

IVIM imaging has been successfully applied for differentiation not only between benign and malignant salivary gland lesions [38] but also for discrimination of other types of tumours in this region. The perfusion-related parameter values have been significantly different among different types of head and neck tumours, including squa- 
mous cell carcinoma, benign (pleomorphic adenomas, Warthin tumour) and malignant salivary gland tumours, lymphomas, and schwannomas [39].

Additionally, low pre-treatment $D$ and $f$ values favour good response to treatment, whereas an increase in $D$ during treatment confirms good response to therapy [40]. However, the role of IVIM MRI in characterisation of lymph nodes remains controversial because IVIM parameters have been shown to be inappropriate for differentiation between metastatic and non-metastatic head and neck lymph nodes [41]. On the other hand, some studies indicate that IVIM DWI is feasible in the diagnosis of lymph node metastasis, which demonstrate decreased $D$ (due to increased nuclear-to-cytoplasmic ratio) and increased $D^{*}$ (due to new blood vessel formation and increased parenchymal perfusion) [42].

Furthermore, pre-treatment and mid-treatment IVIMDWI led to the conclusion that there is a potential for prediction of chemo-radiotherapy response of cervical lymph nodes in head and neck squamous cell carcinoma patients [43].

What is more, in patients with head and neck squamous cell carcinoma (HNSCC) due to locoregional failure, high initial $f$ in lymph nodes may be considered as an indicator of poor treatment response [44].

IVIM MRI (perfusion-related coefficients) appears promising for noninvasive evaluation of early changes of irradiated major salivary glands during radiotherapy [45]. Moreover, it is reasonable and advantageous for predicting and assessing initial responses of human papilloma virus and oropharyngeal squamous cell carcinoma SCC to chemoradiotherapy [46].

Reported artifacts, specific for this area and related to the presence of bones and air-filled structures, are additional problem in the evaluation of the head and neck with MRI. Moreover, specific artifacts related to jaw movements, swallowing, speaking, coughing, and respiration might additionally degrade acquired images.

\section{Breast}

In recent years, with the improved MR hardware, a renewed interest in IVIM has been shown and the applications of IVIM to breast lesions have been reported [47].

According to some authors, IVIM has been recognised as a very promising method for the diagnosis of breast cancer $[48,51,52]$.

Compared to DWI with monoexponential fit, IVIM provides separate quantitative measurement for cellularity and vascularity. IVIM can be used to differentiate benign and malignant lesions with high specificity. This method can increase the diagnostic sensitivity and might play a role in screening breast MRI in high-risk women [47].

What is more, quantification of perfusion fraction, tissue diffusivity, and pseudodiffusivity provides noninvasive sensitivity to microenvironment properties without need of contrast agent. These applications have the potential to improve the specificity of breast MRI.

According to Sigmund et al., further work in a larger patient population is needed to validate the ability of IVIM for the diagnosis, differentiation, monitoring, and management of cancerous lesions in the breast and verify its role as a possible surrogate marker of the biological properties of the tumour [49].

\section{Other lymph nodes}

Some recent studies have shown that particular IVIM parameters, such as the ADC and diffusion coefficient $(D)$, are significantly different between patients with metastatic and non-metastatic lung cancer that has spread to the lymph nodes, therefore possibly facilitating discrimination of benign and malignant mediastinal lymph nodes [53].

Furthermore, an IVIM sequence may also be helpful in diagnosing metastatic lymph nodes of rectal carcinoma. According to Qui, average $D$ and ADC values are more sensitive than $f$ and $D^{*}$ values for this purpose [54]. As reported by Yu et al. in patients with rectal cancer, metastatic mesorectal lymph nodes exhibit lower $D$ and $D^{*}$ values, compared to non-metastatic lymph nodes. The authors concluded that IVIM DWI may be helpful in identifying mesorectal nodal involvement in rectal cancer patients [55].

\section{Clinical applications in neuroradiology}

There is little doubt that IVIM imaging has potential for evaluation of brain ischaemia. Wirestam et al., who utilised IVIM for the assessment of the stroke by IVIM, reported that the perfusion fraction was reduced in areas affected by ischaemia in comparison to the respective contralateral region [56].

In acute stroke, a significant decrease in $f$ was measured in the infarct core compared with the contralateral hemisphere in three independent studies [57-59].

Furthermore, it has been found that decreased IVIM perfusion fraction $f$ and blood flow-related parameter $D^{*}$ might correspond with proximal artery vasospasm development after cerebral aneurysm rupture and delayed cerebral ischaemia [60].

What is more, IVIM may be a valid and favourable method for significant measurement of brain perfusion without intravenous administration of contrast material. According to some studies, IVIM perfusion parameters are highly reactive to hyperoxygenation-induced vasoconstriction and hypercapnia-induced vasodilatation [61].

Another study showed that IVIM can be used for the assessment of cerebral small vessel disease and its complications including lacunar stroke, leukoaraiosis, or even vascular dementia [62]. 


\section{Brain tumours}

The most common malignant brain tumours are gliomas, which originate from glial cells (astrocytes, oligodendrocytes and ependymocytes). Due to the high mortality rate, early diagnosis and correct assessment of the grade of a glioma are crucial for the planning of a therapeutic strategy and establishing a prognosis $[62,63]$.

Researchers reported that both $D^{*}$ and $f$ could be used to differentiate gliomas because these parameters were higher in high-grade gliomas (HGG; WHO: III-IV) in comparison to low-grade gliomas (LGG; WHO: I-II) $[16,64]$. In subsequent reports the authors concluded that IVIM-derived metrics characterising both perfusion $\left(D^{*}, f\right)$ and diffusion $(D)$ have been assessed as promising imaging biomarkers in preoperative differentiation of glioma grades. The $f$ times $D^{*}$ value demonstrated the best diagnostic performance in grading gliomas compared with other parameters and was the only parameter showing a significant difference between grade III and grade IV [65]. Additionally, according to some scientists IVIM metrics could be a potential biomarker for survival in patients with glioblastomas as it has been found out that $f$ and $\mathrm{D}^{*}$ measured in contrast-enhancing regions correlate well with response to therapy and survival [66].

It is also worth noticing that there are studies showing that IVIM may be used to differentiate between glioblastoma and primary central nervous system lymphoma (PCNSL) $[19,67,68]$. According to authors mean maxi- mum $f$ is significantly higher in the glioblastoma group than in the atypical primary central nervous system lymphoma that often mimics glioblastoma $[67,68]$.

The most recent studies showed that the $f$-value can be used as a noninvasive quantitative imaging measure to directly assess the vascular volume fraction in brain tumours. Moreover, one study showed an obvious correlation with the histological vascular density in meningiomas [69].

Moreover, IVIM parameters have been used to monitor the tumours treated with antiangiogenic and vascular target agents that have been recently considered an alternative or complementary therapy to conventional cancer treatments [45,62,70-73].

According to some authors, IVIM may be used to differentiate radiation necrosis from tumour progression in brain metastases that are treated with stereotactic radiotherapy (radiosurgery). The $f$-value was found to be low in the region of the radiation necrosis, whereas tumour recurrence was more heterogeneous and showed higher values [74].

\section{Other clinical applications}

IVIM MR imaging might also be used as a diagnostic tool in gynaecology, orthopaedics, dermatology, and ophthalmology. Presentation of these applications is beyond the scope of this paper; however, some examples of various clinical applications according to the PubMed database are presented in Table 3.

Table 3. Clinical applications of intravoxel incoherent motion magnetic resonance imaging

\begin{tabular}{|c|c|c|}
\hline Neuroradiology & Oncology & Other \\
\hline Cerebral infarction & Brain tumors & $\begin{array}{l}\text { Renal function, e.g. renal fibrosis, early changes } \\
\text { in diabetic kidneys }\end{array}$ \\
\hline Brain perfusion & Primary and non-metastatic head and neck tumors & Cardiac imaging \\
\hline \multirow[t]{13}{*}{$\begin{array}{l}\text { Pulsatility of the brain's } \\
\text { microvasculature }\end{array}$} & Lymph nodal metastasis & Dermatomyositis imaging \\
\hline & Pancreatic lesions & Human Achilles tendon imaging \\
\hline & Prostate lesions & Lactating breast lesion imaging \\
\hline & Breast tumors & Orbital lesions imaging \\
\hline & Liver lesions & Vertebral bone marrow imaging \\
\hline & Renal lesions & Thyroid benign and malignant nodule differentiation \\
\hline & Cervical cancer & Tissue characterization of the uterine fibroids \\
\hline & Soft tissue tumors & Ischemic optic neuropathy \\
\hline & Diagnosis of pediatric solid abdominal tumors & Temporomandibular joint disorder imaging \\
\hline & $\begin{array}{l}\text { Monitoring treatment efficacy of chemo- or radiotherapy, } \\
\text { effectiveness of antiangiogenic drugs and vascular targeting agents }\end{array}$ & $\begin{array}{l}\text { Knee joint in children with juvenile idiopathic } \\
\text { arthritis imaging }\end{array}$ \\
\hline & & $\begin{array}{l}\text { Invasive fungal infection in the lung treatment } \\
\text { response imaging }\end{array}$ \\
\hline & & $\begin{array}{l}\text { Parotid gland imaging in patients with Sjögren } \\
\text { diasease }\end{array}$ \\
\hline & & Placental perfusion imaging \\
\hline
\end{tabular}




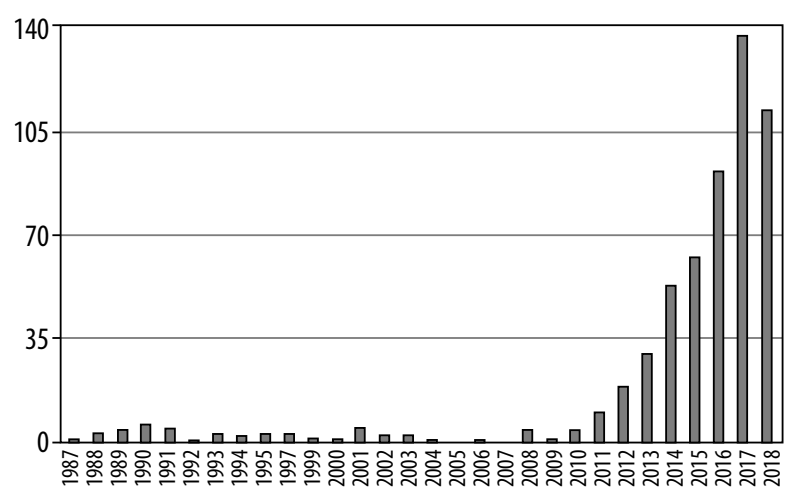

Figure 3. Number of articles about intravoxel incoherent motion magnetic resonance imaging 1987-2018 (PubMed)

\section{Conclusions}

The IVIM method is a DW MRI technique incorporating low $b$-values $\left(<200 \mathrm{~s} / \mathrm{mm}^{2}\right)$ for the estimation of perfusion parameters, which offers many advantages in comparison to the conventionally used DWI technique. It is a noninvasive substitute for the measurement of perfusion that does not require intravenous injection of exogenous contrast agents, such

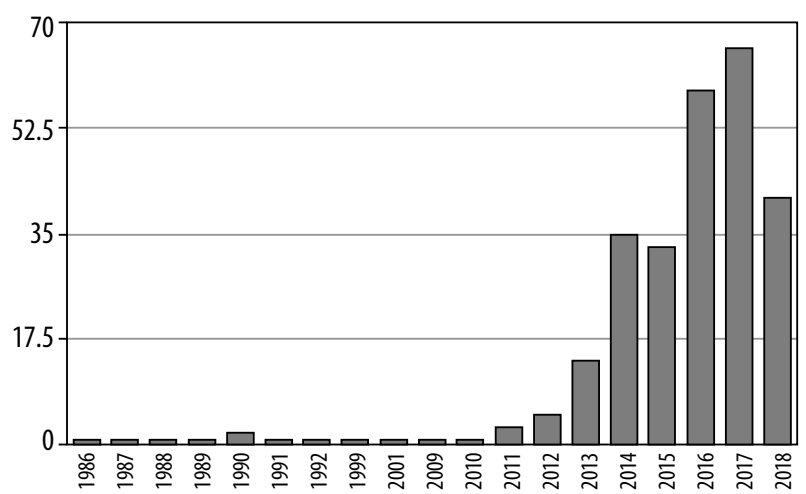

Figure 4. Number of articles about intravoxel incoherent motion magnetic resonance imaging in oncology 1986-2018 (PubMed)

as gadolinium, and can be a great source of information on perfusion and diffusion simultaneously [62].

Today, the most promising clinical application for IVIM perfusion MRI is oncology. The graphs demonstrate the number of articles on implementation of IVIM MRI in oncology (Figure 3), compared to the total number of articles about this technique published between 1986 and 2018 (Figure 4).

Table 4. Characteristics of the included studies

\begin{tabular}{|c|c|c|c|c|c|c|c|c|}
\hline Autor & Lesion & Parameter & Parameter value & Sensitivity & Specificity & Accuracy & AUC & $P$ value \\
\hline \multirow{6}{*}{$\begin{array}{l}\text { Chandarana } \\
\text { et al. [32] }\end{array}$} & \multirow[t]{4}{*}{ Clear cell RCC } & $A D C \times 10^{-3} \mathrm{~mm}^{2} / \mathrm{s}$ & $2.2 \pm 0.4$ & $92.9 \%$ & $58.3 \%$ & $76.9 \%$ & 0.67 & \\
\hline & & $\mathrm{D} \times 10^{-3} \mathrm{~mm}^{2} / \mathrm{s}$ & $1.8 \pm 0.6$ & $86 \%$ & $62.5 \%$ & $75.0 \%$ & 0.68 & \\
\hline & & $f$ & $0.25 \pm 0.05$ & $100 \%$ & $62.5 \%$ & $82.7 \%$ & 0.74 & \\
\hline & & $D^{*} \times 10^{-3} \mathrm{~mm}^{2} / \mathrm{s}$ & $19 \pm 13.5$ & & & & 0,53 & \\
\hline & Cystic RCC and papillary RCC & $f$ & $<0.16$ & & & $100 \%$ & & \\
\hline & $\begin{array}{l}\text { Clear cell RCC and } \\
\text { chromophobe RCC }\end{array}$ & $f$ & $>0.16$ & & & $100 \%$ & & \\
\hline \multirow[t]{4}{*}{ Ding et al. [35] } & \multirow{4}{*}{$\begin{array}{l}\text { Papillary RCC and } \\
\text { chromophobe RCC } \\
\text { vs. fat poor AML }\end{array}$} & $A D C$ & $>1.39$ & $39.1 \%$ & $100 \%$ & $60.0 \%$ & 0.634 & 0.167 \\
\hline & & $\mathrm{D}$ & $>0.97$ & $56.5 \%$ & $100 \%$ & $71.4 \%$ & 0.757 & 0.002 \\
\hline & & $D^{*}$ & $\leq 28.03$ & $87.0 \%$ & $75 \%$ & $82.9 \%$ & 0.822 & $<0.001$ \\
\hline & & $\mathrm{f}$ & $\leq 13.61$ & $43.5 \%$ & $100 \%$ & $62.9 \%$ & 0.783 & $<0.001$ \\
\hline \multirow[t]{12}{*}{ Sumi et al. [38] } & \multirow[t]{3}{*}{ Normal parotid gland } & $\mathrm{D}, \times 10^{-3} \mathrm{~mm}^{2} / \mathrm{s}$ & $0.765 \pm 0.138$ & & & & & \\
\hline & & $f$ & $0.148 \pm 0.043$ & & & & & \\
\hline & & $D^{*}, \times 10^{-3} \mathrm{~mm}^{2} / \mathrm{s}$ & $41.68 \pm 21.91$ & & & & & \\
\hline & \multirow[t]{3}{*}{ Normal submandibular gland } & $\mathrm{D}, \times 10^{-3} \mathrm{~mm}^{2} / \mathrm{s}$ & $0.999 \pm 0.154$ & & & & & \\
\hline & & $f$ & $0.133 \pm 0.037$ & & & & & \\
\hline & & $\mathrm{D}^{*}, \times 10^{-3} \mathrm{~mm}^{2} / \mathrm{s}$ & $54.16 \pm 23.24$ & & & & & \\
\hline & \multirow{3}{*}{$\begin{array}{l}\text { Malignant salivary gland } \\
\text { tumor }\end{array}$} & $\mathrm{D}, \times 10^{-3} \mathrm{~mm}^{2} / \mathrm{s}$ & $0.96 \pm 0.22$ & & & & & \\
\hline & & $f$ & $0.103 \pm 0.0050$ & & & & & \\
\hline & & $D^{*}, \times 10^{-3} \mathrm{~mm}^{2} / \mathrm{s}$ & $21.99 \pm 19.01$ & & & & & \\
\hline & \multirow[t]{3}{*}{ Pleomorphic adenoma } & $\mathrm{D}, \times 10^{-3} \mathrm{~mm}^{2} / \mathrm{s}$ & $1.38 \pm 0.30$ & & & & & \\
\hline & & $\mathrm{f}$ & $0.066 \pm 0.031$ & & & & & \\
\hline & & $D^{*}, \times 10^{-3} \mathrm{~mm}^{2} / \mathrm{s}$ & $10.53 \pm 3.48$ & & & & & \\
\hline
\end{tabular}


Table 4. Cont.

\begin{tabular}{|c|c|c|c|c|c|c|c|c|}
\hline Autor & Lesion & Parameter & Parameter value & Sensitivity & Specificity & Accuracy & AUC & $P$ value \\
\hline & \multirow[t]{3}{*}{ Warthin tumor } & $\mathrm{D}, \times 10^{-3} \mathrm{~mm}^{2} / \mathrm{s}$ & $0.61 \pm 0.11$ & & & & & \\
\hline & & $f$ & $0.156 \pm 0.039$ & & & & & \\
\hline & & $\mathrm{D}^{*}, \times 10^{-3} \mathrm{~mm}^{2} / \mathrm{s}$ & $42.64 \pm 20.17$ & & & & & \\
\hline & \multirow{3}{*}{$\begin{array}{l}\text { Discriminating pleomorphic } \\
\text { adenomas from Warthin tumors }\end{array}$} & $\mathrm{D}, \times 10^{-3} \mathrm{~mm}^{2} / \mathrm{s}$ & $\geq 1.1$ & $100 \%$ & $100 \%$ & $100 \%$ & & \\
\hline & & $f$ & $\leq 0.1$ & $83 \%$ & $100 \%$ & $90 \%$ & & \\
\hline & & $\mathrm{D}^{*}, \times 10^{-3} \mathrm{~mm}^{2} / \mathrm{s}$ & $\leq 23$ & $100 \%$ & $100 \%$ & $100 \%$ & & \\
\hline & \multirow{3}{*}{$\begin{array}{l}\text { Discriminating malignant } \\
\text { salivary gland tumors from } \\
\text { benign ones }\end{array}$} & $\mathrm{D}, \times 10^{-3} \mathrm{~mm}^{2} / \mathrm{s}$ & $0.8<D<1.1$ & $64 \%$ & $100 \%$ & $87 \%$ & & \\
\hline & & $\mathrm{D}^{*}, \times 10^{-3} \mathrm{~mm}^{2} / \mathrm{s}$ & $10 \leq D^{*} \leq 23$ & $73 \%$ & $65 \%$ & $68 \%$ & & \\
\hline & & $\begin{array}{l}\text { Combined } D \text { and } D^{*} \text {, } \\
\quad \times 10^{-3} \mathrm{~mm}^{2} / \mathrm{s}\end{array}$ & $\begin{array}{c}0.8<D<1.1, D \leq 0,8 \\
\text { and } D^{*} \leq 23, \text { or } 1.1 \leq D<1.4 \\
\text { and } D^{*} \geq 12\end{array}$ & $100 \%$ & $100 \%$ & $100 \%$ & & \\
\hline \multirow[t]{12}{*}{ Sumi et al. [39] } & \multirow[t]{2}{*}{ Lymphomas } & $\begin{array}{l}\text { PP perfusion- } \\
\text { related parameter }\end{array}$ & $0.09 \pm 0.04$ & & & & & \\
\hline & & $\mathrm{D}, \times 10^{-3} \mathrm{~mm}^{2} / \mathrm{s}$ & $0.47 \pm 0.07$ & & & & & \\
\hline & \multirow[t]{2}{*}{ Malignant salivary gland tumors } & PP & $0.22 \pm 0.07$ & & & & & \\
\hline & & $\mathrm{D}, \times 10^{-3} \mathrm{~mm}^{2} / \mathrm{s}$ & $1.03 \pm 0.16$ & & & & & \\
\hline & \multirow[t]{2}{*}{ Squamous cell carcinomas } & PP & $0.15 \pm 0.04$ & & & & & \\
\hline & & $\mathrm{D}, \times 10^{-3} \mathrm{~mm}^{2} / \mathrm{s}$ & $0.82 \pm 0.17$ & & & & & \\
\hline & \multirow[t]{2}{*}{ Pleomorphic adenomas } & PP & $0.13 \pm 0.02$ & & & & & \\
\hline & & $\mathrm{D}, \times 10^{-3} \mathrm{~mm}^{2} / \mathrm{s}$ & $1.44 \pm 0.39$ & & & & & \\
\hline & \multirow[t]{2}{*}{ Schwannomas } & PP & $0.23 \pm 0.08$ & & & & & \\
\hline & & $\mathrm{D}, \times 10^{-3} \mathrm{~mm}^{2} / \mathrm{s}$ & $1.26 \pm 0.20$ & & & & & \\
\hline & \multirow[t]{2}{*}{ Warthin tumors } & PP & $0.19 \pm 0.04$ & & & & & \\
\hline & & $\mathrm{D}, \times 10^{-3} \mathrm{~mm}^{2} / \mathrm{s}$ & $0.73 \pm 0.22$ & & & & & \\
\hline \multirow[t]{4}{*}{$\begin{array}{l}\text { Liang L et AL. } \\
(42)\end{array}$} & \multirow[t]{4}{*}{$\begin{array}{l}\text { Malignant lymph nodes vs } \\
\text { benign lymph nodes }\end{array}$} & $D^{*}, \times 10^{-3} \mathrm{~mm}^{2} / \mathrm{s}$ & $\begin{array}{c}120.89 \pm 26.94 \\
\text { vs. } 68.78 \pm 17.72 \\
\end{array}$ & & & & & 0.0001 \\
\hline & & $\mathrm{D}, \times 10^{-3} \mathrm{~mm}^{2} / \mathrm{s}$ & $0.57 \pm 0.12$ vs. $0.74 \pm 0.21$ & & & & & 0.0001 \\
\hline & & $f(\%)$ & $0.20 \pm 0.02$ vs. $0.32 \pm 0.05$ & & & & & 0.0001 \\
\hline & & $\mathrm{ADC}, \times 10^{-3} \mathrm{~mm}^{2} / \mathrm{s}$ & $1.08 \pm 0.26$ vs. $1.25 \pm 0.19$ & & & & & 0.035 \\
\hline \multirow[t]{2}{*}{$\begin{array}{l}\text { Federau et al. } \\
\text { [57] }\end{array}$} & \multirow[t]{2}{*}{$\begin{array}{l}\text { Acute ischemic stroke - brain } \\
\text { infarct core vs. contralateral side }\end{array}$} & $f$ & $\begin{array}{c}0.026 \pm 0.019 \\
\text { vs. } 0.056 \pm 0.025\end{array}$ & & & & & $2.2 \times 10^{-6}$ \\
\hline & & $\mathrm{D}, \mathrm{mm}^{2} / \mathrm{s}$ & $\begin{array}{c}3.9 \pm 0.79 \times 10^{-4} \\
\text { vs. } 7.5 \pm 0.86 \times 10^{-4}\end{array}$ & & & & & $1.3 \times 10^{-20}$ \\
\hline \multirow[t]{5}{*}{ Suo et al. [58] } & \multirow{5}{*}{$\begin{array}{l}\text { Ischemic stroke vs contralateral } \\
\text { hemisphere }\end{array}$} & $\mathrm{ADC}, \times 10^{-3} \mathrm{~mm}^{2} / \mathrm{s}$ & $0.43 \pm 0.10$ vs. $0.73 \pm 0.07$ & & & & & $<0.001$ \\
\hline & & $\mathrm{D}, \times 10^{-3} \mathrm{~mm}^{2} / \mathrm{s}$ & $0.42 \pm 0.10$ vs. $0.72 \pm 0.07$ & & & & & $<0.001$ \\
\hline & & $D^{*}, \times 10^{-3} \mathrm{~mm}^{2} / \mathrm{s}$ & $10.20 \pm 4.17$ vs. $10.87 \pm 4.75$ & & & & & 0.218 \\
\hline & & $f(\%)$ & $4.29 \pm 2.01$ vs. $7.97 \pm 2.03$ & & & & & $<0.001$ \\
\hline & & $\mathrm{fD}^{*}, \times 10^{-3} \mathrm{~mm}^{2} / \mathrm{s}$ & $0.49 \pm 0.27$ vs. $0.94 \pm 0.42$ & & & & & $<0.001$ \\
\hline \multirow{4}{*}{$\begin{array}{l}\text { Togao et al. } \\
{[64]}\end{array}$} & \multirow{4}{*}{$\begin{array}{l}\text { Differentiating high-grade } \\
\text { gliomas from low-grade gliomas }\end{array}$} & $\mathrm{D}, \times 10^{-3} \mathrm{~mm}^{2} / \mathrm{s}$ & $\leq 1.25$ & $100 \%$ & $56.2 \%$ & & 0.78 & \\
\hline & & $A D C, \times 10^{-3} \mathrm{~mm}^{2} / \mathrm{s}$ & $\leq 1.29$ & $96.6 \%$ & $50.0 \%$ & & 0.73 & \\
\hline & & $\mathrm{D}^{*}, \times 10^{-3} \mathrm{~mm}^{2} / \mathrm{s}$ & $\geq 8.43$ & $75.9 \%$ & $50.0 \%$ & & 0.60 & \\
\hline & & $f(\%)$ & $\geq 7.7$ & $96.6 \%$ & $81.2 \%$ & & 0.95 & \\
\hline Suh et al. [67] & $\begin{array}{l}\text { Glioblastoma group vs. } \\
\text { atypical primary central } \\
\text { nervous system lymphoma }\end{array}$ & $f_{\max }$ & $\begin{array}{l}\text { reader } 1: 0.101 \pm 0.016 \\
\quad \text { vs. } 0.021 \pm 0.010 \\
\text { reader } 2: 0.107 \pm 0.024 \\
\text { vs. } 0.027 \pm 0.015\end{array}$ & $\begin{array}{c}\text { reader 1: } \\
89.5 \% \\
\text { reader 2: } \\
84.2 \%\end{array}$ & $\begin{array}{c}\text { reader 1: } \\
95.1 \% \\
\text { reader 2: } \\
95.1 \%\end{array}$ & & & $\begin{array}{l}\text { reader 1: } \\
<0.001 \\
\text { reader } 2 \text { : } \\
<0.001\end{array}$ \\
\hline
\end{tabular}


Table 4. Cont.

\begin{tabular}{|c|c|c|c|c|c|c|c|c|}
\hline Autor & Lesion & Parameter & Parameter value & Sensitivity & Specificity & Accuracy & AUC & $P$ value \\
\hline \multirow[t]{12}{*}{ Liu et al. [10] } & \multirow[t]{4}{*}{ Breast malignant tumor } & $\mathrm{ADC}, \times 10^{-3} \mathrm{~mm}^{2} / \mathrm{s}$ & $0.95(0.83,1.06)$ & $93 \%$ & $90 \%$ & & & \\
\hline & & $\mathrm{D}, \times 10^{-3} \mathrm{~mm}^{2} / \mathrm{s}$ & $0.85(0.77,0.98)$ & $90 \%$ & $93 \%$ & & & \\
\hline & & $f$ & $10.34(7.68,11.88)$ & $88 \%$ & $54 \%$ & & & \\
\hline & & $\mathrm{D}^{*}, \times 10^{-3} \mathrm{~mm}^{2} / \mathrm{s}$ & $94.71(70.33,113.23)$ & $85 \%$ & $41 \%$ & & & \\
\hline & \multirow[t]{4}{*}{ Breast benign lesions } & $\mathrm{ADC}, \times 10^{-3} \mathrm{~mm}^{2} / \mathrm{s}$ & $1.39(1.32,1.50)$ & $95 \%$ & $90 \%$ & & & \\
\hline & & $\mathrm{D}, \times 10^{-3} \mathrm{~mm}^{2} / \mathrm{s}$ & $1.99(1.77,2.03)$ & $92 \%$ & $96 \%$ & & & \\
\hline & & $f$ & $6.83(4.72,10.33)$ & $89 \%$ & $56 \%$ & & & \\
\hline & & $\mathrm{D}^{*}, \times 10^{-3} \mathrm{~mm}^{2} / \mathrm{s}$ & $107.49(83.20,131.19)$ & $82 \%$ & $44 \%$ & & & \\
\hline & \multirow[t]{4}{*}{ Breast simple cyst } & $\mathrm{ADC}, \times 10^{-3} \mathrm{~mm}^{2} / \mathrm{s}$ & $1.96(1.73,2.18)$ & & & & & \\
\hline & & $\mathrm{D}, \times 10^{-3} \mathrm{~mm}^{2} / \mathrm{s}$ & $1.35(1.26,1.44)$ & & & & & \\
\hline & & $f$ & $1.69(0.70,3.47)$ & & & & & \\
\hline & & $\mathrm{D}^{*}, \times 10^{-3} \mathrm{~mm}^{2} / \mathrm{s}$ & $99.33(87.04,155.69)$ & & & & & \\
\hline \multirow{4}{*}{$\begin{array}{l}\text { Valerio et al. } \\
\text { [24] }\end{array}$} & \multirow[t]{4}{*}{ Prostate cancer } & $A D C, \times 10^{-3} \mathrm{~mm}^{2} / \mathrm{s}$ & $0.76 \pm 0.27$ & & & & & \\
\hline & & $D_{1} \times 10^{-3} \mathrm{~mm}^{2} / \mathrm{s}$ & $0.99 \pm 0.38$ & & & & & \\
\hline & & $f$ & $9.35 \pm 5.97$ & & & & & \\
\hline & & $D^{*}, \times 10^{-3} \mathrm{~mm}^{2} / \mathrm{s}$ & $15.56 \pm 12.91$ & & & & & \\
\hline \multirow{15}{*}{$\begin{array}{l}\text { Yamada et al. } \\
\text { [28] }\end{array}$} & \multirow[t]{4}{*}{$\mathrm{HCC}$} & $A D C, \times 10^{-3} \mathrm{~mm}^{2} / \mathrm{s}$ & $1.10 \pm 0.18$ & & & & & \\
\hline & & $\mathrm{D}, \times 10^{-3} \mathrm{~mm}^{2} / \mathrm{s}$ & $1.02 \pm 10.17$ & & & & & \\
\hline & & $f$ & $0.15 \pm 10.07$ & & & & & \\
\hline & & $D^{*}, \times 10^{-3} \mathrm{~mm}^{2} / \mathrm{s}$ & & & & & & \\
\hline & \multirow[t]{4}{*}{ Liver metastasis } & $\mathrm{ADC}, \times 10^{-3} \mathrm{~mm}^{2} / \mathrm{s}$ & $1.26 \pm 0.25$ & & & & & \\
\hline & & $\mathrm{D}, \times 10^{-3} \mathrm{~mm}^{2} / \mathrm{s}$ & $1.16 \pm 0.18$ & & & & & \\
\hline & & $f$ & $0.22 \pm 0.09$ & & & & & \\
\hline & & $D^{*}, \times 10^{-3} \mathrm{~mm}^{2} / \mathrm{s}$ & & & & & & \\
\hline & \multirow[t]{4}{*}{ Liver hemangioma } & $A D C, \times 10^{-3} \mathrm{~mm}^{2} / \mathrm{s}$ & $1.56 \pm 0.22$ & & & & & \\
\hline & & $\mathrm{D}, \times 10^{-3} \mathrm{~mm}^{2} / \mathrm{s}$ & $1.31 \pm 0.21$ & & & & & \\
\hline & & $f$ & $0.35 \pm 0.10$ & & & & & \\
\hline & & $D^{*}, \times 10^{-3} \mathrm{~mm}^{2} / \mathrm{s}$ & & & & & & \\
\hline & \multirow[t]{3}{*}{ Liver cyst } & $A D C, \times 10^{-3} \mathrm{~mm}^{2} / \mathrm{s}$ & $3.01 \pm 0.28$ & & & & & \\
\hline & & $\mathrm{D}, \times 10^{-3} \mathrm{~mm}^{2} / \mathrm{s}$ & $3.03 \pm 0.22$ & & & & & \\
\hline & & $f$ & $0.00 \pm 0.01$ & & & & & \\
\hline \multirow{12}{*}{$\begin{array}{l}\text { De Robertis et } \\
\text { al. [29] }\end{array}$} & \multirow[t]{4}{*}{ Pancreatic cancer } & $A D C, \times 10^{-3} \mathrm{~mm}^{2} / \mathrm{s}$ & $1.41(1.02-1.73)$ & & & & & \\
\hline & & $\mathrm{D}, \times 10^{-3} \mathrm{~mm}^{2} / \mathrm{s}$ & $1.42(0.87-1.97)$ & $77 \%$ & $88 \%$ & & 0.821 & \\
\hline & & $f$ & $5.82(2.12-18.84)$ & $91 \%$ & $100 \%$ & & 0.989 & \\
\hline & & $D^{*}, \times 10^{-3} \mathrm{~mm}^{2} / \mathrm{s}$ & $10.23(1.79-57.85)$ & $94 \%$ & $96 \%$ & & 0.952 & \\
\hline & \multirow[t]{4}{*}{ Neuroendocrine neoplasms } & $A D C, \times 10^{-3} \mathrm{~mm}^{2} / \mathrm{s}$ & $1.28(1.01-1.89)$ & & & & & \\
\hline & & $D, \times 10^{-3} \mathrm{~mm}^{2} / \mathrm{s}$ & $1.2(0.54-1.56)$ & & & & & \\
\hline & & $f$ & $27.61(3.22-80.83)$ & & & & & \\
\hline & & $D^{*}, \times 10^{-3} \mathrm{~mm}^{2} / \mathrm{s}$ & $28.9(12.16-73.08)$ & & & & & \\
\hline & \multirow[t]{4}{*}{ Autoimmune pancreatitis } & $\mathrm{ADC}, \times 10^{-3} \mathrm{~mm}^{2} / \mathrm{s}$ & $1.24(0.94-1.64)$ & & & & & \\
\hline & & $\mathrm{D}, \times 10^{-3} \mathrm{~mm}^{2} / \mathrm{s}$ & $1.16(0.84-1.76)$ & & & & & \\
\hline & & $f$ & $9.87(4.18-11.60)$ & $100 \%$ & $100 \%$ & & 1.000 & \\
\hline & & $D^{*}, \times 10^{-3} \mathrm{~mm}^{2} / \mathrm{s}$ & $10.62(7.6-15.15)$ & $100 \%$ & $98 \%$ & & 0.988 & \\
\hline
\end{tabular}

$A D C$ - apparent diffusion coefficient; $D$ - diffusion coefficient; $D^{*}$ - pseudodiffusion coefficient; $f$ - perfusion fraction; AUC - area under curve; $R C C$ - renal cell carcinoma; $A M L$ - angiomyolipoma; HCC - hepatocellular carcinoma; PP - perfusion-related parameter. 
Recently, there has been greater interest in using the IVIM technique to examine organ function and to evaluate treatment response. There is growing evidence that the additional functional information related to tumour angiogenesis may assist diagnosis and could have prognostic value in oncology patients.

Applications of IVIM may include detection and characterisation of widespread disease, such as both primary and metastatic tumours.

Published studies indicate that, in the near future, IVIM may become an important diagnostic imaging modality to evaluate brain, head and neck, salivary gland, pancreatic, prostate, breast, liver, and renal lesions, as well as lymph node metastasis [2].

However, the main problem with implementation of IVIM for routine MR imaging is lack of standardisation of both image acquisition and analysis, resulting in significant variance in calculated parameters among studies [75,76] (Table 4). Thus, this technique still needs to be refined in terms of acquisition, analysis, and application.

\section{Conflict of interest}

The authors report no conflict of interest.

\section{References}

1. Le Bihan D, Breton E, Lallemand D, et al. Separation of diffusion and perfusion in intravoxel incoherent motion MR imaging. Radiology 1988; 168: 497-505.

2. Iima M, Le Bihan D. Clinical intravoxel incoherent motion and diffusion MR imaging: past, present, and future. Radiology 2016; 278: 13-32.

3. Li YT, Cercueil JP, Yuan J, et al. Liver intravoxel incoherent motion (IVIM) magnetic resonance imaging: a comprehensive review of published data on normal values and applications for fibrosis and tumor evaluation. Quant Imaging Med Surg 2017; 7: 59-78.

4. Le Bihan D, Johansen-Berg H. Diffusion MRI at 25: exploring brain tissue structure and function. Neuroimage 2012; 61: 324-341.

5. Le Bihan D. What can we see with IVIM MRI? Neuroimage 2019; 187: 56-67.

6. Park HJ, Sung YS, Lee SS, et al. Intravoxel incoherent motion diffusion-weighted MRI of the abdomen: the effect of fitting algorithms on the accuracy and reliability of the parameters. J Magn Reson Imaging 2017; 45: 1637-1647.

7. Lemke A, Stieltjes B, Schad L, Laun F. Toward an optimal distribution of $\mathrm{b}$ values for intravoxel incoherent motion imaging. Magn Reson Imaging 2011; 29: 766-776.

8. Barbieri S, Donati OF, Froehlich JM, et al. Comparison of intravoxel incoherent motion parameters across MR imagers and field strengths: evaluation in upper abdominal organs. Radiology 2016; 279: 784-794.

9. Guo W, Luo D, Lin M, et al. Pretreatment intra-voxel incoherent motion diffusion-weighted imaging (IVIM-DWI) in predicting induction chemotherapy response in locally advanced hypopharyngeal carcinoma. Medicine (Baltimore) 2016; 95: e3039.

10. Liu C, Liang C, Liu Z, et al. Intravoxel incoherent motion (IVIM) in evaluation of breast lesions: comparison with conventional DWI. Eur J Radiol 2013; 82: e782-789.

11. Ichikawa S, Motosugi U, Ichikawa T, et al. Intravoxel incoherent motion imaging of the kidney: alterations in diffusion and perfusion in patients with renal dysfunction. Magn Reson Imaging 2013; 31: 414-417.

12. Rheinheimer S, Stieltjes B, Schneider F, et al. Investigation of renal lesions by diffusion-weighted magnetic resonance imaging applying intravoxel incoherent motion-derived parameters - initial experience. Eur J Radiol 2012; 81: e310-316.

13. Cui Y, Dyvorne H, Besa C, et al. IVIM diffusion-weighted imaging of the liver at 3.0T: comparison with 1.5T. Eur J Radiol Open 2015; 2: 123-128.
14. Dyvorne HA, Galea N, Nevers T, et al. Diffusion-weighted imaging of the liver with multiple $b$ values: effect of diffusion gradient polarity and breathing acquisition on image quality and intravoxel incoherent motion parameters - a pilot study. Radiology 2013; 266: 920-929.

15. Federau C, O’Brien K, Meuli R, et al. Measuring brain perfusion with intravoxel incoherent motion (IVIM): initial clinical experience. J Magn Reson Imaging 2014; 39: 624-632.

16. Federau C, Meuli R, O'Brien K, et al. Perfusion measurement in brain gliomas with intravoxel incoherent motion MRI. AJNR Am J Neuroradiol 2014; 35: 256-262.

17. Döpfert J, Lemke A, Weidner A, Schad LR. Investigation of prostate cancer using diffusion-weighted intravoxel incoherent motion imaging. Magn Reson Imaging 2011; 29: 1053-1058.

18. Kakite S, Dyvorne HA, Lee KM, et al. Hepatocellular carcinoma: IVIM diffusion quantification for prediction of tumor necrosis compared to enhancement ratios. Eur J Radiol Open 2015; 3: 1-7.

19. Shim WH, Kim HS, Choi CG, Kim SJ. Comparison of apparent diffusion coefficient and intravoxel incoherent motion for differentiating among glioblastoma, metastasis, and lymphoma focusing on diffusion-related parameter. PLoS One 2015; 10: e0134761.

20. Conklin J, Heyn C, Roux M, et al. A simplified model for intravoxel incoherent motion perfusion imaging of the brain. AJNR Am J Neuroradiol 2016; 37: 2251-2257.

21. Federau C, Cerny M, Roux M, et al. IVIM perfusion fraction is prognostic for survival in brain glioma. Clin Neuroradiol 2017; 27: 485-492.

22. Xu XQ, Choi YJ, Sung YS, et al. Intravoxel incoherent motion MR imaging in the head and neck: correlation with dynamic contrastenhanced MR imaging and diffusion-weighted imaging. Korean J Radiol 2016; 17: 641-649.

23. Boss A, Barth B, Filli L, et al. Simultaneous multi-slice echo planar diffusion weighted imaging of the liver and the pancreas: optimization of signal-to-noise ratio and acquisition time and application to intravoxel incoherent motion analysis. Eur J Radiol 2016; 85: 1948-1955.

24. Valerio M, Zini C, Fierro D, et al. 3T multiparametric MRI of the prostate: does intravoxel incoherent motion diffusion imaging have a role in the detection and stratification of prostate cancer in the peripheral zone? Eur J Radiol 2016; 85: 790-794.

25. Pang Y, Turkbey B, Bernardo M, et al. Intravoxel incoherent motion MR imaging for prostate cancer: an evaluation of perfusion fraction 
and diffusion coefficient derived from different b-value combinations. Magn Reson Med 2013; 69: 553-562.

26. Bane O, Wagner M, Zhang JL, et al. Assessment of renal function using intravoxel incoherent motion diffusion-weighted imaging and dynamic contrast-enhanced MRI. J Magn Reson Imaging 2016; 44: 317-326.

27. Luciani A, Vignaud A, Cavet M, et al. Liver cirrhosis: intravoxel incoherent motion MR imaging - pilot study. Radiology 2008; 249: 891-899.

28. Yamada I, Aung W, Himeno Y, et al. Diffusion coefficients in abdominal organs and hepatic lesions: evaluation with intravoxel incoherent motion echo-planar MR imaging. Radiology 1999; 210: 617-623.

29. De Robertis R, Cardobi N, Ortolani S, et al. Intravoxel incoherent motion diffusion-weighted MR imaging of solid pancreatic masses: reliability and usefulness for characterization. Abdom Radiol (NY) 2019; 44: 131-139.

30. Chiaradia M, Baranes L, Van Nhieu JT, et al. Intravoxel incoherent motion (IVIM) MR imaging of colorectal liver metastases: are we only looking at tumor necrosis? J Magn Reson Imaging 2014; 39: 317-325.

31. Re TJ, Lemke A, Klauss M, et al. Enhancing pancreatic adenocarcinoma delineation in diffusion derived intravoxel incoherent motion f-maps through automatic vessel and duct segmentation. Magn Reson Med 2011; 66: 1327-1332.

32. Chandarana H, Kang SK, Wong S, et al. Diffusion-weighted intravoxel incoherent motion imaging of renal tumors with histopathologic correlation. Invest Radiol 2012; 47: 688-696.

33. Campbell N, Rosenkrantz AB, Pedrosa I. MRI phenotype in renal cancer: is it clinically relevant? Top Magn Reson Imaging 2014; 23: 95-115.

34. Wu Y, Kwon YS, Labib M, et al. Magnetic resonance imaging as a biomarker for renal cell carcinoma. Dis Markers 2015; 2015: 648495.

35. Ding Y, Zeng M, Rao S, et al. Comparison of biexponential and monoexponential model of diffusion-weighted imaging for distinguishing between common renal cell carcinoma and fat poor angiomyolipoma. Korean J Radiol 2016; 17: 853-863.

36. Johnson LM, Turkbey B, Figg WD, Choyke PL. Multiparametric MRI in prostate cancer management. Nat Rev Clin Oncol 2014; 11: 346-353.

37. Shinmoto H, Tamura C, Soga S, et al. An intravoxel incoherent motion diffusion-weighted imaging study of prostate cancer. AJR Am J Roentgenol 2012; 199: W496-500.

38. Sumi M, Van Cauteren M, Sumi T, et al. Salivary gland tumors: use of intravoxel incoherent motion MR imaging for assessment of diffusion and perfusion for the differentiation of benign from malignant tumors. Radiology 2012; 263: 770-777.

39. Sumi M, Nakamura T. Head and neck tumors: assessment of perfusion-related parameters and diffusion coefficients based on the intravoxel incoherent motion model. AJNR Am J Neuroradiol 2013; 34: 410-416.

40. Noij DP, Martens RM, Marcus JT, et al. Intravoxel incoherent motion magnetic resonance imaging in head and neck cancer: A systematic review of the diagnostic and prognostic value. Oral Oncol 2017; 68: 81-91.

41. Hejduk B, Bobek-Billewicz B, Rutkowski T, et al. Application of intravoxel incoherent motion (IVIM) model for differentiation between metastatic and non-metastatic head and neck lymph nodes. Pol J Radiol 2017; 82: 506-510.

42. Liang L, Luo X, Lian Z, et al. Lymph node metastasis in head and neck squamous carcinoma: efficacy of intravoxel incoherent motion magnetic resonance imaging for the differential diagnosis. Eur J Radiol 2017; 90: 159-165.
43. Marzi S, Piludu F, Sanguineti G, et al. The prediction of the treatment response of cervical nodes using intravoxel incoherent motion diffusion-weighted imaging. Eur J Radiol 2017; 92: 93-102.

44. Hauser T, Essig M, Jensen A, et al. Prediction of treatment response in head and neck carcinomas using IVIM-DWI: evaluation of lymph node metastasis. Eur J Radiol 2014; 83: 783-787.

45. Marzi S, Forina C, Marucci L, et al. Early radiation-induced changes evaluated by intravoxel incoherent motion in the major salivary glands. J Magn Reson Imaging 2015; 41: 974-982.

46. Ding Y, Hazle JD, Mohamed AS, et al. Intravoxel incoherent motion imaging kinetics during chemoradiotherapy for human papillomavirus-associated squamous cell carcinoma of the oropharynx: preliminary results from a prospective pilot study. NMR Biomed 2015; 28 : 1645-1654.

47. Liu C, Liang C, Liu Z, et al. Intravoxel incoherent motion (IVIM) in evaluation of breast lesions: comparison with conventional DWI. Eur J Radiol 2013; 82: e782-e789.

48. Iima M, Yano K, Kataoka M, et al. Quantitative non-Gaussian diffusion and intravoxel incoherent motion magnetic resonance imaging: differentiation of malignant and benign breast lesions. Invest Radiol 2015; 50: 205-211.

49. Sigmund EE, Cho GY, Kim S, et al. Intravoxel incoherent motion imaging of tumor microenvironment in locally advanced breast cancer. Magn Reson Med 2011; 65: 1437-1447.

50. Iima M, Le Bihan D, Okumura R, et al. Apparent diffusion coefficient as an MR imaging biomarker of low-risk ductal carcinoma in situ: a pilot study. Radiology 2011; 260: 364-372.

51. Kamitani T, Hatakenaka M, Yabuuchi H, et al. Detection of axillary node metastasis using diffusion-weighted MRI in breast cancer. Clin Imaging 2013; 37: 56-61.

52. Luo N, Su D, Jin G, et al. Apparent diffusion coefficient ratio between axillary lymph node with primary tumor to detect nodal metastasis in breast cancer patients. J Magn Reson Imaging 2013; 38: 824-828.

53. Ye X, Chen S, Tian Y, et al. A preliminary exploration of the intravoxel incoherent motion applied in the preoperative evaluation of mediastinal lymph node metastasis of lung cancer. J Thorac Dis 2017; 9: 10731080.

54. Qiu L, Liu XL, Liu SR, et al. Role of quantitative intravoxel incoherent motion parameters in the preoperative diagnosis of nodal metastasis in patients with rectal carcinoma. J Magn Reson Imaging 2016; 44 : 1031-1039.

55. Yu XP, Wen L, Hou J, et al. Discrimination between metastatic and nonmetastatic mesorectal lymph nodes in rectal cancer using intravoxel incoherent motion diffusion-weighted magnetic resonance imaging. Acad Radiol 2016; 23: 479-485.

56. Wirestam R, Brockstedt S, Lindgren A, et al. The perfusion fraction in volunteers and in patients with ischaemic stroke. Acta Radiol 1997; 38: 961-964.

57. Federau C, Sumer S, Becce F, et al. Intravoxel incoherent motion perfusion imaging in acute stroke: initial clinical experience. Neuroradio$\operatorname{logy} 2014 ; 56: 629-635$.

58. Suo S, Cao M, Zhu W, et al. Stroke assessment with intravoxel incoherent motion diffusion-weighted MRI. NMR Biomed 2016; 29: 320-328.

59. Yao Y, Zhang S, Tang X, et al. Intravoxel incoherent motion diffusion-weighted imaging in stroke patients: initial clinical experience. Clin Radiol 2016; 71: 938.e11-16. 
60. Heit JJ, Wintermark M, Martin BW, et al. Reduced intravoxel incoherent motion microvascular perfusion predicts delayed cerebral ischemia and vasospasm after aneurysm rupture. Stroke 2018; 49: 741-745.

61. Federau C, Maeder P, O’Brien K, Browaeys P, Meuli R, Hagmann P. Quantitative measurement of brain perfusion with intravoxel incoherent motion MR imaging. Radiology 2012; 265: 874-881.

62. Paschoal AM, Leoni RF, Dos Santos AC, Paiva FF. Intravoxel incoherent motion MRI in neurological and cerebrovascular diseases. Neuroimage Clin 2018; 20: 705-714.

63. Louis DN, Perry A, Reifenberger G, et al. The 2016 World Health Organization classification of tumors of the central nervous system: a summary. Acta Neuropathol 2016; 131: 803-820.

64. Togao O, Hiwatashi A, Yamashita K, et al. Differentiation of high-grade and low-grade diffuse gliomas by intravoxel incoherent motion MR imaging. Neuro Oncol 2016; 18: 132-141.

65. Shen N, Zhao L, Jiang J, et al. Intravoxel incoherent motion diffusion-weighted imaging analysis of diffusion and microperfusion in grading gliomas and comparison with arterial spin labeling for evaluation of tumor perfusion. J Magn Reson Imaging 2016; 44: 620-632.

66. Puig J, Sanchez-Gonzalez J, Blasco G, et al. Intravoxel incoherent motion metrics as potential biomarkers for survival in glioblastoma. PLoS One 2016; 11: e0158887.

67. Suh CH, Kim HS, Lee SS, et al. Atypical imaging features of primary central nervous system lymphoma that mimics glioblastoma: utility of intravoxel incoherent motion MR imaging. Radiology 2014; 272: 504-513.

68. Yamashita K, Hiwatashi A, Togao O, et al. Diagnostic utility of intravoxel incoherent motion $\mathrm{mr}$ imaging in differentiating primary central nervous system lymphoma from glioblastoma multiforme. J Magn Reson Imaging 2016; 44: 1256-1261.

69. Togao O, Hiwatashi A, Yamashita K, et al. Measurement of the perfusion fraction in brain tumors with intravoxel incoherent motion MR imaging: validation with histopathological vascular density in meningiomas. Br J Radiol 2018; 91: 20170912.

70. Cui Y, Zhang C, Li X, et al. Intravoxel incoherent motion diffusion-weighted magnetic resonance imaging for monitoring the early response to ZD6474 from nasopharyngeal carcinoma in nude mouse. Sci Rep 2015; 5: 16389.

71. Joo I, Lee JM, Grimm R, et al. Monitoring vascular disrupting therapy in a rabbit liver tumor model: relationship between tumor perfusion parameters at IVIM diffusion-weighted MR imaging and those at dynamic contrast-enhanced MR imaging. Radiology 2016; 278: 104-113.

72. Joo I, Lee JM, Han JK, Choi BI. Intravoxel incoherent motion diffusion-weighted MR imaging for monitoring the therapeutic efficacy of the vascular disrupting agent CKD-516 in rabbit VX2 liver tumors. Radiology 2014; 272: 417-426.

73. Yang SH, Lin J, Lu F, et al. Evaluation of antiangiogenic and antiproliferative effects of sorafenib by sequential histology and intravoxel incoherent motion diffusion-weighted imaging in an orthotopic hepatocellular carcinoma xenograft model. J Magn Reson Imaging 2017; 45 : 270-280.

74. Detsky JS, Keith J, Conklin J, et al. Differentiating radiation necrosis from tumor progression in brain metastases treated with stereotactic radiotherapy: utility of intravoxel incoherent motion perfusion MRI and correlation with histopathology. J Neurooncol 2017; 134: 433-441.

75. Yablonskiy DA, Sukstanskii AL. Theoretical models of the diffusion weighted MR signal. NMR Biomed 2010; 23: 661-681.
76. Cieszanowski A, Pasicz K, Podgórska J, et al. Reproducibility of intravoxel incoherent motion of liver on a 3.0T scanner: free-breathing and respiratory-triggered sequences acquired with different numbers of excitations. Pol J Radiol 2018; 83: e437-e445. 